\title{
A formação de professores da educação básica a partir do programa escolas interculturais de fronteira (PEIF) na região fronteiriça Brasil-Paraguai
}

\author{
The training of basic education teachers from the frontier \\ intercultural schools (PEIF) program in the Brazil- Paraguai \\ frontier region
}

Mara Lucinéia Marques Correa Bueno ${ }^{1}$ Kellcia Rezende Souza ${ }^{2}$

Resumo: $O$ presente artigo objetiva analisar o Programa Escolas Interculturais de Fronteira (PEIF) como uma política supranacional de formação continuada para os professores da educação básica com vista à integração regional na região fronteiriça Brasil-Paraguai. Trata-se de uma pesquisa bibliográfica, documental e de campo com o enfoque qualitativo. $\mathrm{O}$ instrumento empregado em campo para coleta de dados foi o grupo focal com professores e profissionais da educação participantes do PEIF de uma instituição de ensino localizada no sul do estado de Mato Grosso do Sul. Os

${ }^{1}$ Doutora e Mestre em Educação pela Universidade Federal da Grande Dourados - UFGD, especialista em Metodologia da Educação Infantil e Anos Iniciais do Ensino Fundamental pelas Faculdades Integradas de Amambai / MS, possui graduação em Pedagogia pelas Faculdades Magsul de Ponta Porã / MS e apostilamento no curso de Pedagogia Faculdades Integradas de Amambai / MS. Desde 2014 é docente adjunta do Curso de Pedagogia da Universidade Federal de Mato Grosso do Sul - Câmpus de Ponta Porã / MS.

2 Possui Licenciatura em Educação Física pela Universidade Federal de Goiás (2009) e Licenciatura em Pedagogia pela Universidade Metropolitana de Santos (2015). Mestre em Educação pela Universidade Federal da Grande Dourados (2012). Doutora em Educação Escolar pela Universidade Estadual Paulista - Unesp/Araraquara (2017). Foi servidora pública Técnico-administrativa da Universidade Federal da Grande Dourados (UFGD) de 2010 à 2016. Foi membro titular entre 2013 à 2016 do Fórum Nacional de Educação do Ministério da Educação (MEC) do Brasil. É, desde 2017, docente adjunta da Faculdade de Educação da UFGD e realiza atividades de ensino, pesquisa e extensão voltadas para as áreas de Políticas públicas educacionais e gestão escolar.

Interfaces da Educ., Paranaíba, v.11, n.32, p. 244 - 270, 2020 
resultados evidenciados apontam dois cenários: o primeiro é a sinalização do PEIF como um programa inovador quanto à formação específica de professores que atuam em regiões fronteiriças ao considerar as particularidades presentes nesses contextos; já o segundo, demonstra que a falta de continuidade e a baixa adesão ao programa pelas escolas foram fatores que impossibilitaram a consolidação do PEIF enquanto uma política supranacional de integração regional.

Palavras-chave: educação de fronteira. formação de professores. política educacional.

Abstract: This article aims to analyze the Intercultural Schools of Frontier Program (PEIF) as a supranational policy of continuing education for basic education teachers with a view to regional integration in the Brazil-Paraguay border region. It is a bibliographic, documentary and field research with a qualitative focus. The instrument used in the field for data collection was the focus group with teachers and education professionals participating in the PEIF of an educational institution located in the south of the state of Mato Grosso do Sul. The evidenced results point to two scenarios: the first is the signaling PEIF as an innovative program regarding the specific training of teachers who work in border regions when considering the particularities present in these contexts; the second, on the other hand, demonstrates that the lack of continuity and the low adherence to the program by schools were factors that made it impossible to consolidate PEIF as a supranational policy of regional integration.

Keywords: frontier education. teacher training. educational politics. 


\section{Introdução}

A instituição de políticas voltadas para a região de fronteira é um fenômeno recente no âmbito educacional, já que no Brasil não existia legislação que atendesse as especificidades regionais antes da criação do Mercado Comum do Sul (MERCOSUL) em 1991 e do Setor Educacional do Mercosul (SEM) no âmbito dos países sul-americanos.

O Mercosul foi criado pelo Tratado de Assunção em 1991, com o objetivo de promover a livre circulação de bens, serviços e capitais entre os países do Cone Sul - Argentina, Brasil, Paraguai e Uruguai ${ }^{1}$, por meio da eliminação dos direitos alfandegários e restrições não tarifárias de mercadorias. Trata-se de um pacto regional para o fortalecimento econômico dos respectivos países. Em 2012, a Venezuela ingressou como quinto país membro do bloco (SOUZA, 2017).

Embora o Mercosul corresponda a "acordo que abarca eminentemente o setor econômico e comercial, incorpora, desde o início, outros setores que possuem estrita relação com o desenvolvimento político, econômico e social dos Estados que o integram, dentre eles, a educação" (SOUZA, 2017, p. 25). Para a autora, a pauta educacional no âmbito do bloco foi incorporada a partir da criação do Setor Educacional do Mercosul, que consiste em um espaço institucionalizado de coordenação das politicas educacionais entre os seus respectivos países membros.

Nessa direção, o presente artigo representa um recorte da pesquisa de doutoramento já concluída sobre a execução do Programa Escolas Interculturais de Fronteira (PEIF) na fronteira do Brasil com o Paraguai, mais especificamente, na região sul do Estado de Mato Grosso do Sul (MS), por apresentar a única escola da região a participar do Programa. Esse status foi conferido a esta escola por ter alterado sua proposta pedagógica e

\footnotetext{
$1 \mathrm{O}$ recorte do estudo delimita apenas os países pertencentes ao Mercosul. Dessa forma, não atentar-se-á à discussão dos Estados Associados (Chile, Bolivia, Colômbia, Equador e Peru), assim como os demais países latino-americanos, cuja realidade econômica, social e, dentro desta, educacional, apresenta muitos traços de similaridade (BABINSKI, 2010).
}

Interfaces da Educ., Paranaíba, v.11, n.32, p. 244 - 270, 2020 
realizado o cruce (intercâmbio) com uma escola paraguaia. O problema de pesquisa corresponde ao seguinte questionamento: O PEIF contribuiu com a formação continuada de professores das escolas de fronteira no que se refere à interculturalidade e ao multilinguismo?

Cumpre ressaltar que, em sua maioria, as pesquisas relacionadas ao PEIF advêm da linguística, sendo poucas exclusivas da área da educação. Uma maneira de compreender esta realidade volta-se para os próprios documentos do Ministério da Educação (MEC) e do Programa que apontam como eixos para o desenvolvimento das ações os levantamentos sociolinguísticos e o bilinguismo. Esta realidade justifica a necessidade de estudos na área da educação sobre a região de fronteira na perspectiva das políticas e gestão da educação. Diante do exposto, a presente investigação tem como objetivo analisar o PEIF como uma política supranacional de formação continuada para os professores com vista à integração regional e ao multilinguismo, no caso desta pesquisa o Brasil e o Paraguai.

Considerando que o Programa Escolas Bilíngues de Fronteira (PEBF) (BRASIL, 2008) e o PEIF (BRASIL, 2012) foram as primeiras iniciativas voltadas para as especificidades fronteiriças, cabe trazer à discussão questões pertinentes a essa realidade, tais como: a interculturalidade e o bilinguismo. Em específico, na região pesquisada, trata-se do multilinguismo devido a presença do Espanhol e do Guarani como línguas maternas do Paraguai e a Língua Portuguesa como oficial do Brasil.

O eixo central do trabalho proposto pelos Programas refere-se ao desenvolvimento da interculturalidade, a construção da identidade fronteiriça e o ensino em línguas. Por este motivo o cruce, que se tratava do professor brasileiro que ministrava aulas na escola parceira do país vizinho (Paraguai) e vice-versa, representou a culminância da integração dos países via escola (STURZA, 2014).

O PEBF propunha um assessoramento pedagógico e formação continuada essencialmente prática com os professores das escolas e turmas 
participantes do Programa mensalmente sob responsabilidade do Instituto de Investigação e Política Linguística (IPOL), além da realização do cruce entre escolas e turmas de ambos os países. Já o PEIF, instituído pela Portaria n. 798/2012, foi realizado em parceria entre Ministério da Educação (MEC), Universidades públicas, Secretarias Estaduais e Municipais de Educação e escolas de fronteira, e propunha o acompanhamento pedagógico e a realização de formação continuada aos professores das escolas, bem como turmas participantes do Programa, semanalmente. O PEIF visava a fundamentação teórica do trabalho de construção da identidade fronteiriça, desenvolvimento da interculturalidade e do multilinguismo (BRASIL, 2012). É importante registrar que na fronteira do Brasil com o Paraguai, durante a vigência do PEIF, não houve cruce.

\section{Políticas de formação de professores da região de fronteira: a regulamentação do PEIF}

O Brasil buscou, ao longo de sua história educacional, normatizar leis que dessem amparo a formação de professores. Contudo, todas as políticas voltadas para a formação de professores não mencionavam especificidades regionais, como a região de fronteira. Baller (2014) salienta que as politicas são geridas em ambientes neutros e que a fronteira apresenta suas particularidades:

\footnotetext{
Pensar as relações fronteiriças apenas pelos meandros políticos, a partir de tratados, convênios, acordos e outros artificios de um poder que, na realidade, não está localizado na fronteira, e sim nas capitais do Estado demonstra a fragilidade na percepção da fronteira pelas pessoas e instituições que deliberam sobre suas questões. Justamente porque as relações fronteiriças ocorrem na fronteira e não nos espaços de discussões políticas. Nesse sentido alguns projetos que se materializam fora das fronteiras surgem como verdadeiras utopias e não atendem às necessidades dos fronteiriços e às especificidades da fronteira (BALLER, 2014, p. 306-307).
} 
Cabe salientar que as legislações pensadas para a formação de professores no Brasil não contemplaram ações específicas para a fronteira antes do PEBF e do PEIF. Os únicos documentos oficiais que trataram da formação continuada se referem ao PEBF (BRASIL, 2008) e PEIF (BRASIL, 2012), respectivamente, que foram programas educacionais que tiveram na formação continuada de professores o ponto central para o trabalho com a interculturalidade e o multilinguismo presente na fronteira. Ou seja, há uma escassez de legislação para amparar uma política educacional específica para a região de fronteira. Lorenzetti e Torquato (2016, p. 89) explicitam que o PEBF foi reformulado para o Mercosul Educacional surgindo assim o PEIF, "mas o núcleo da proposta intercultural permanece sem modificações".

Nesta perspectiva, o PEBF propunha a integração da comunidade escolar de ambos os países para o desenvolvimento do Programa, respeitando as diferenças culturais a partir de práticas interculturais e multilingues. Este princípio era desenvolvido pelo IPOL (Instituto de Desenvolvimento em Políticas Linguísticas) por meio da formação continuada para os professores atuantes nas escolas participantes do Programa e assessoramento pedagógico. O PEBF ainda apresentava a educação para a zona de fronteira tendo como eixo central as linguas, no caso a Língua Portuguesa e o Espanhol, pois nesta região torna-se comum o uso de ambos os idiomas para a comunicação entre os povos.

Sobre a questão linguística, Sturza (2014) salienta que quando a escola de fronteira se identifica como intercultural e expõe-se aos saberes e conhecimentos de diferentes formas há um aprendizado gerado a partir das dúvidas dos alunos. Neste momento, as línguas ocupam um lugar importante na troca de experiências e mudanças de atitudes, pois permitem desconstruir preconceitos relacionados a língua materna do país vizinho.

Por este motivo, o contato entre professores e alunos dos países envolvidos do PEBF é importante e, esta relação visava ser estabelecida a partir do cruce (intercâmbio) entre professores e, consequentemente, a 
possibilidade de despertar a curiosidade dos alunos sobre o outro país (BRASIL, 2008). No entender de Sturza (2014), o intercâmbio apresentava um significado relevante ao desenvolvimento intercultural da fronteira:

\begin{abstract}
O "cruce" é a travessia, que em algumas fronteiras é a ponte; em outras, a balsa; em outra, apenas a rua. Mas cruzar, na dinâmica proposta para esse programa, é muito mais, pois coloca o professor no centro do processo à medida que é ele que leva a língua, a cultura e o conhecimento, mediando-os com os alunos da escola parceira. O professor articula, planeja e desenvolve projetos em conjunto com o colega argentino, paraguaio, venezuelano e uruguaio (STURZA, 2014, p. 05).
\end{abstract}

O processo de integração regional, a construção da identidade fronteiriça, bem como, o desenvolvimento da interculturalidade e do multilinguismo eram os principios do $\mathrm{PEBF}$, os quais permaneceram ao iniciar o PEIF com a publicação da Portaria n. 798/2012. O PEIF contemplava os países pertencentes ao Mercosul e propôs a parceria com as universidades federais para o desenvolvimento da formação continuada para professores, conforme previsto no art. n. 8 da Portaria n. 798/2012. A formação continuada tinha por princípio sensibilizar o professor a desenvolver um modelo de ensino comum para a zona de fronteira presente na proposta da escola reflexiva (BRASIL, 2012).

Nesta perspectiva, a escola reflexiva leva o professor a pensar sua prática e, assim, recriar a escola buscando construir sua identidade, valorizar seu potencial enquanto instituição mediadora do conhecimento para trazer a visão partilhada da realidade mediante a reflexão de forma sistemática sobre as práticas pedagógicas (ALARCÃO, 2001). Moreira (2013) acrescenta que atrelada à escola reflexiva está a aprendizagem significativa, que para David P. Ausubel ${ }^{2}$, representa uma aprendizagem com significado.

\footnotetext{
$2 \mathrm{O}$ modelo proposto por Ausubel exige a incorporação de novos conceitos e informações em uma estrutura congnitiva que se organiza de uma forma particular. O paradigma de transferência aplica-se aqui e transferência refere-se ao impacto da experiência prévia sobre a aprendizagem atual (RONCA, 1994, p. 93).
} 
Contudo, a Portaria n. 798/2012 não explicita se o Programa será desenvolvido na perspectiva da escola reflexiva, mas o programa anterior ao PEIF, o PEBF, apresentava diretrizes que sinalizavam nessa direção (BRASIL, 2008). Como o PEIF trata-se da ampliação da proposta do PEBF, houve a continuidade das ações, antes entre Brasil e Argentina, e posteriormente, com a inclusão do Paraguai e Uruguai.

Portanto, o PEBF e o PEIF revelaram-se como um marco para as escolas de fronteira, ao trazer à tona a questão da interculturalidade e do bilinguismo, que estão presentes na fronteira, mas são desconhecidas pelo restante do país. Nesse sentido, o PEIF representou uma política supranacional de formação continuada de professores atuantes em região de fronteira ao propor um trabalho diferenciado na busca da integração regional, da construção da identidade fronteiriça, bem como, no desenvolvimento da interculturalidade e do multilinguismo.

A relação estabelecida entre o $\mathrm{MEC}$, as universidades e as escolas configura-se em um regime de colaboração e parceria, como já mencionado anteriormente, pois o Governo Federal estava representado em cada cidade situada na faixa de fronteira ou fronteiriça por meio de uma Universidade Federal, que realizava as formações continuadas com os professores atuantes nas escolas participantes do PEIF.

A responsabilidade do MEC sobre o PEIF limitava-se a articulação entre as universidades, Secretarias Estaduais e Municipais de Educação e as escolas fronteiriças que aderissem ao Programa. Logo, o PEIF, em sua essência, projetava a integração do MEC, por meio das universidades, com as escolas e professores, onde a proposta da Portaria n. 798/2012 previa uma formação continuada em que o professor fronteiriço tivesse a oportunidade de rever sua prática e postura em sala de aula frente à realidade peculiar da fronteira. 


\section{Metodologia}

A pesquisa apresentou como escolha metodológica a avaliação de uma politica pública educacional e seus possiveis impactos que, para Palumbo (1989, p. 50), representa o quarto estágio em um ciclo de políticas, onde são avaliados o "impacto da política e os processos pelas quais ela está sendo implementada".

Ao trazer o estudo sobre o PEIF como uma politica supranacional, recorre-se a Mainardes (2006) para contextualizar que os profissionais de educação tem um papel fundamental na interpretação e reinterpretação das politicas públicas educacionais, já que estes trazem implicações ao processo de desenvolvimento das politicas. Para tanto, os sujeitos dessa pesquisa são os professores atuantes no PEIF da Escola selecionada.

O desenvolvimento do estudo foi conduzido pela abordagem qualitativa e subsidiado em todas as suas fases pela pesquisa bibliográfica. Considerando que a discussão sobre as escolas em regiões de fronteiras é recente no âmbito normativo, o levantamento bibliográfico também evidenciou a carência de discussões sobre a temática. Nesse sentido, a pesquisa documental foi necessária, pois conforme Cellard (2014, p. 299) é "[...] essencial saber compor com algumas fontes documentais, mesmo as mais pobres, pois elas são geralmente as únicas que podem nos esclarecer, um pouco que seja, sobre uma situação determinada”.

Utilizou-se da técnica de investigação científica de grupo focal. Para isso, recorreu-se a Gondim (2003, p. 150) para fundamentar a aplicação do grupo focal com viés qualitativo, no qual se enfatiza que "o homem é capaz de refletir sobre si mesmo e, através das interações sociais, construir-se como pessoa". Cabe, ainda, salientar que o uso desta técnica não busca um consenso, mas as diferentes opiniões sobre o PEIF e vislumbra uma orientação para um determinado campo de foco, assim como, gerar e coletar dados qualitativos sobre as atitudes, valores e opiniões sobre o Programa. 
Realizou-se o grupo focal com 7 integrantes, obedecendo alguns critérios de seleção dos profissionais como: ser professor (a) efetivo (a) da escola selecionada, com maior tempo de serviço na rede pública de ensino e participante da formação continuada do PEIF. As características dos sujeitos selecionados estão apresentadas no Quadro 1, a seguir.

\section{Quadro 1 - Caracterização dos participantes do Grupo Focal}

\section{Profissão Sigla de}

identificação

\begin{tabular}{ccc}
\hline Pedagoga & P1 (2018) & 35 anos \\
\hline Pedagoga & P2 (2018) & 33 anos \\
\hline Arte-Educadora & AE (2018) & anos \\
\hline Educadora Física & EF (2018) & 12 anos \\
\hline Linguísta - hab. & A (2018) - & \\
Espanos & 30 anos \\
Coordenadora & articuladora do PEIF & \\
Pedagógica & CP (2018) & 25 anos \\
\hline Linguísta - hab. & T (2018) - tutora & \\
Espanhol & do PEIF &
\end{tabular}

Fonte: Elaboração própria das pesquisadoras a partir da realização do grupo focal.

Todos os sujeitos selecionados concederam anuência (Termo de consentimento livre e esclarecido) para participar da investigação. Assim, foram utilizadas letras para identificar cada participante do grupo focal e manter o anonimato dos profissionais envolvidos por questões éticas vinculadas a pesquisa. Cumpre esclarecer que, apesar dos critérios de seleção estabelecidos, concidentemente, todas as selecionadas são mulheres. Já a escolha de apenas uma Escola para a realização da pesquisa limitou-se ao fato de que esta foi a única unidade educativa da região sul mato- 
grossense que executou o PEBF e o PEIF durante a vigência destes dois Programas.

Os diálogos do grupo focal foram gravados em áudio (SCHRAIBER, 1995) com a autorização dos participantes e, posteriormente, transcritos para análise (PRETTI; URBANO, 1988). Para Richardson (2008, p. 71) é fundamental compreender que "esse tipo de estudo deve ser realizado quando o pesquisador deseja obter melhor entendimento do comportamento de diversos fatores e elementos que influem sobre determinado fenômeno".

E, para ajustar as informações de conteúdo, adequadamente, coletadas no grupo focal utilizou-se da análise de conteúdo (BARDIN, 2016). É relevante explicitar que há diferentes fases neste periodo de experimentação e que estão vinculadas a polos cronológicos, a saber: 1) préanálise, 2) exploração do material e a 3) tratamento dos resultados, inferência e a interpretação.

A pré-análise antecede a escrita propriamente dita e apresenta-se como missão a escolha dos documentos a serem analisados no estudo, a formulação de hipótese e dos objetivos, bem como a elaboração de indicadores que auxiliarão na interpretação dos dados coletados. Já a fase de exploração do material representa a análise em si com a aplicação das escolhas realizadas na fase anterior. $\mathrm{E}$ a fase do tratamento dos dados simboliza a coleta de resultados, em estado bruto, que após serem tratados (analisados) trarão respostas significativas ao trabalho. Após esses procedimentos de análise de conteúdo, foi evidenciada a necessidade de organizar as informações coletadas por meio de categorias.

Carlomagno e Rocha (2016, p. 175) apontam que "[...] classificar e categorizar qualquer tipo de conteúdo, reduzindo suas características a elementos-chave, de modo com que sejam comparáveis a uma série de outros elementos", pois se torna relevante eleger categorias para mapear o conteúdo das informações coletadas em campo para tratar as evidências de maneira fidedigna e classificá-las por meio da análise de conteúdo.

Interfaces da Educ., Paranaíba, v.11, n.32, p. 244 - 270, 2020 
Contudo, a execução da análise de conteúdo é complexa e se apresenta de maneira implícita, buscando a "categorização (passagem de dados em bruto a dados organizados)" (BARDIN, 2016, p. 147). Ainda de acordo com a autora, a categorização simboliza uma operação de classificação dos elementos constitutivos de um conjunto por diferenciação, ou seja, representa classificar em categorias as informações coletadas nas entrevistas e no grupo focal.

E, para analisar os dados coletados buscou-se em Saldaña (2013) meios de categorizar e codificar. Para este autor, a codificação é um processo para a análise qualitativa de dados, relacionando-se com o campo de pesquisa, além das opções teóricas e recortes conceituais do pesquisador. Cumpre recordar que se trata de um recorte de uma pesquisa maior realizada, por isso os dados empíricos explícitos no texto não se apresentam em sua integralidade.

Desta forma, a categoria a ser analisada neste estudo foi denominada de política de formação continuada de professores que representou o ponto alto da pesquisa, com a qual se pode mensurar o impacto do PEIF a partir do olhar dos envolvidos sobre como o Programa foi desenvolvido na fronteira investigada e considerando, também, as peculiaridades locais.

\section{Resultados}

Inicialmente foi proposto às professoras que relatassem, brevemente, sobre a experiência de cada uma com o PEIF para que se construísse uma condição favorável à participação de todos os componentes, criando assim um ambiente confortável e propenso ao diálogo sobre o tema (GATTI, 2005). Ao propor este momento, $\mathrm{T}$ (2018) iniciou relatando que:

A nossa experiência com o PEIF teve início no fim de 2008 quando começamos a fazer o levantamento sócio linguístico e efetivamente com o curso iniciou em 2009. Para nós foi uma experiência que mudou completamente a postura em relação a várias situações, não só em relação a formação continuada que na sequência a gente já passou a ter mas em relação a própria postura do professor com Interfaces da Educ., Paranaíba, v.11, n.32, p. 244 - 270, 2020 
relação ao aluno, ao tipo de aluno que nós recebemos, as dificuldades que esse aluno trás para a escola, porque ele é falante do espanhol, do guarani como língua materna e isso causa uma série de situações no contexto escolar que antes nós não prestávamos atenção (T, 2018).

A sujeito T (2018) ainda acrescentou:

\begin{abstract}
$\mathrm{E}$, quando a gente passou a fazer o levantamento sócio linguístico e aí perguntar para esses alunos qual lingua que eles falavam, qual eles tinham mais domínio e até mesmo presenciar no contexto da família, porque com o levantamento sócio linguístico nós também visitamos as famílias desses alunos, então percebemos que a dificuldade era grande. E, aí foi todo um movimento que a escola passou a desenvolver, não só em relação aos professores, a solicitação junto a Secretaria por formação continuada, foi trazer a comunidade para discutir essas questões. Tudo isso mudou completamente a rotina da escola tanto que nós tivemos que reestruturar todo o nosso Projeto Político Pedagógico justamente para contemplar essa metodologia que hoje atende até o $3^{\circ}$ ano do ensino médio $(\mathrm{T}, 2018)$.
\end{abstract}

Pereira (2016) e Torchi e Silva (2016) enfatizam que o levantamento sócio linguístico representou um momento de reflexão sobre a importância da língua e da cultura nesse processo educacional. Já Lima (2018), evidencia que a lingua apresenta uma questão de extrema relevância e, por isso, merece políticas especificas:

Deste modo, o constante confronto e a mistura entre as linguas e também entre os falantes, faz da fronteira um local de enunciação de línguas e de produção de saberes, que demanda novos modos de abordagem, o que, por si só, traz uma necessidade de se colocar o fato linguístico dessas regiões para dentro do debate politico (LIMA, 2018. p. 56).

Assim sendo, a iniciativa de politicas educacionais próprias para a fronteira, como a instituição do PEIF, figura como um aporte importante para a realidade peculiar dessa localidade. E, ao envolver os países membros do Mercosul, por meio do SEM, apresenta um avanço ao processo de integração regional. Na sequência, a Articuladora do PEIF aqui denominada de A (2018) tomou a palavra e relatou:

Interfaces da Educ., Paranaíba, v.11, n.32, p. 244 - 270, 2020 
Eu iniciei aqui na escola em 2011, já tinham feito todo o questionário, o levantamento, já estava bem avançado. Então eu comecei como articuladora aqui, que no caso seria acompanhar o desenvolvimento do Programa junto com os professores, auxiliar elas (professores) na questão do desenvolvimento da pesquisa de campo, na prática, transformar teoria em prática. Eu cheguei a vivenciar até um momento que eles ainda faziam cruze, quando os professores saiam daqui e iam para o Paraguai. Então esse trabalho na minha visão quando eu cheguei e agora que eu avancei um pouco mais, ele é inovador, ele é bem diferente daquilo que a gente está acostumado, no início ele foi um desafio (A, 2018).

Nesse momento P1 (2018), interrompeu A (2018) e apontou:

Exatamente, agora eu pego a fala da A (2018), porque o ano que eu entrei aqui foi o mesmo ano da A (2018) e, eu como professora regente já entrei trabalhando na alfabetização, eu uma professora que vem de uma escola tradicionalíssima, então quando eu cheguei aqui eu cai em desespero a ponto de chegar e falar para A (2018), que era minha articuladora, eu não quero mais isso aqui, não sei trabalhar isso, isso é dificil (P1, 2018).

Percebe-se na fala de A (2018) e P1 (2018), que o PEIF representou uma grande mudança na prática pedagógica do professor em sala de aula, pois trouxe um novo olhar para a realidade de fronteira. No entender de Haygert e Sturza (2015, p. 06), o Programa de Escolas Interculturais de Fronteira, "enquanto política linguística visa a expansão das fronteiras a partir de um projeto que propõe por em contato professores e alunos [...] para o desenvolvimento de atividades interculturais em que se promovam as linguas nacionais". Nesse momento, EF (2018) complementou:

AE (2018) enfatizou:

Eu como professora de Artes, para mim foi algo novo, desafiador e muito. Eu comecei aqui na escola em 2011, eu peguei esse momento do curso que foi maravilhoso para mim, eu achei incrivel esse momento dos professores trocarem onde os professores da Escola do Brasil iam até a escola do Paraguai, para os do Paraguai virem aqui dar aulas, achei isso muito bom, inovador (AE, 2018).

Interfaces da Educ., Paranaíba, v.11, n.32, p. 244 - 270, 2020 
Cumpre informar que, como algumas das professoras participaram do PEBF e, posteriormente do PEIF, houve momentos em que as respostas referiam-se a prática do PEBF, como foi o caso expresso acima por $\mathrm{AE}$ (2018). Já P2 (2018) destacou que: "Trabalhei com o PEIF desde o início aqui na Escola, eu ia ao Paraguai e os professores de lá vinham para cá. Eu não tive muita dificuldade porque eu falo o Espanhol e falo o Guarani, então eu não tive muito problema com os alunos" (P2, 2018). Nesse momento, houve a interrupção da fala de P2 (2018) por P1 (2018) que acrescentou:

Eu trabalhava com o $1^{\circ}$ aninho, a alfabetização, então você imagina eu ter que trabalhar uma metodologia diferente onde eu tenho que alfabetizar essas crianças. Então foi muito importante para mim a presença da articuladora do PEIF, porque o meu interesse e a minha vontade, a minha curiosidade de ver se ia dar certo e deu certo, tanto que temos ai resultado de aluno que hoje estão no $9^{\circ}$ ano, no médio e, você vê a diferença do nosso aluno daqui dessa escola para os de outra escola. Então deu certo (P1, 2018).

CP (2018) concordou com todas as demais professoras. A mudança de metodologia realmente foi a maior dificuldade enfrentada pela Escola pesquisada durante o processo de adequação ao PEIF pelos profissionais envolvidos, mas em grande parte os estudos sobre o Programa não abrangeram os obstáculos relacionados a prática pedagógica em sala de aula, conforme Haygert e Sturza (2015) evidenciam:

Esse Programa coloca em funcionamento muitos sentidos no que se refere ao ensino e aprendizagem, que não são discutidos nos documentos. Em meio a todas as ações propostas nos "papéis", encontram-se professores e alunos, sujeitos fronteiriços, que estão reorganizando seu pensamento com relação a muitas questões (HAYGERT E STURZA, 2015, p. 12).

Para as referidas autoras, a existência de formação continuada para professores atuantes em região de fronteira trouxe a reflexão, por exemplo, as especificidades da prática pedagógica nas escolas fronteiriças. Nessa vertente, indagou-se o grupo sobre quais formações continuadas específicas para educação de fronteira participaram ao longo da vida profissional. E Interfaces da Educ., Paranaiba, v.11, n.32, p. 244 - 270, 2020 
todas foram unânimes em afirmar que apenas a formação do PEBF e a do PEIF estavam relacionadas com a educação fronteiriça e foi esta formação que mais chamou a atenção dos docentes. Neste momento, CP (2018) salientou que:

O PEIF, a sua metodologia o desenvolvimento da criança nesta formação foi o que mais me chamou atenção, a aprendizagem mesmo, não era aquela aprendizagem mecânica, era uma aprendizagem que ia além, em que a criança procura o saber dela, isso que mais me encantou, pois parte da criança e não do professor (CP, 2018).

Todas as participantes do grupo disseram que houve outras formações ofertadas as escolas estaduais de MS, mas não relacionadas a educação de fronteira, como o Programa Gestão da Aprendizagem Escolar (GESTAR) ${ }^{3}$ e Projeto Além das Palavras ${ }^{4}$. Ambas as formações encaixam-se na proposta das Diretrizes Curriculares para Formação Inicial e Continuada de Professores, prevista na Resolução MEC/CNE n. 02/2015 no artigo n. 16:

\begin{abstract}
A formação continuada compreende dimensões coletivas, organizacionais e profissionais, bem como o repensar do processo pedagógico, dos saberes e valores, e envolve atividades de extensão, grupos de estudos, reuniões pedagógicas, cursos, programas e ações para além da formação mínima exigida ao exercício do magistério na educação básica, tendo como principal finalidade a reflexão sobre a prática educacional e a busca de aperfeiçoamento técnico, pedagógico, ético e político do profissional docente (BRASIL, 2015).
\end{abstract}

3 O Programa Gestão da Aprendizagem Escolar oferece formação continuada em língua portuguesa e matemática aos professores dos anos finais (do sexto ao nono ano) do ensino fundamental em exercício nas escolas públicas.

${ }^{4}$ A proposta do projeto [...] é capacitar, assessorar e acompanhar professores licenciados ou bacharéis em Pedagogia, no ensino das disciplinas de Língua Portuguesa e Matemática, contemplando o uso de metodologia específica, material didático propício, valorizando as atividades que possibilitam o uso de material concreto, o cotidiano dos educandos e os descritores, ou seja, as habilidades inseridas no desenvolvimento dos exercícios utilizados nas Avaliações Nacionais dos conteúdos das disciplinas citadas (BERNARDO, 2012, p. 02).

Interfaces da Educ., Paranaíba, v.11, n.32, p. 244 - 270, 2020 
E, também encontram-se em consonância com a Política Nacional de Formação dos Profissionais da Educação Básica, sancionado pelo Decreto n. 8.752/2016. Logo, apenas em 2016 normatiza-se o regime de colaboração entre os entes federados, mas desde 2012, com a instituição do PEIF, havia a parceria entre MEC, universidades e escolas públicas para o desenvolvimento de ações educacionais na fronteira.

Evidencia-se que o PEBF e o PEIF foram as únicas políticas de formação continuada de professores específicas para a região de fronteira. Sendo assim, comprova-se que as ações educacionais fronteiriças limitaramse aos Programas vinculados ao SEM, mediante acordo firmado no âmbito do Mercosul.

Nesse sentido, as professoras do grupo focal enfatizaram o significado da formação continuada do PEIF, AE (2018) foi a primeira a relatar que "Tirar a gente da zona de conforto, é uma das primeiras coisas" (AE, 2018). Já P1 (2018), completou "Total transformação, acredito eu dentro da educação" e EF (2018) enfatizou "Uma mudança de visão" (EF, 2018). Mas A (2018) foi além, disse:

[...] fazer você respeitar as diferenças culturais porque antigamente ficava preso "Brasil é Brasil" acho que isso foi o que mais me marcou. É você ver que não é Brasil, é uma fronteira. E você tem várias culturas diferentes dentro de uma sala de aula (A, 2018).

P1 (2018) pediu novamente a fala e acrescentou:

\begin{abstract}
E havia um pecado muito grande também em relação a nós professores da alfabetização porque quando eu cheguei aqui nós tínhamos muitas crianças do Paraguai e antigamente eu tinha uma certa visão "se ele não me entende ai o problema é da criança" e o PEIF fez eu mudar a visão (P1, 2018).
\end{abstract}

As demais CP (2018), P2 (2018) e T (2018) enfatizaram que havia preconceito com o aluno paraguaio, mas com o desenvolvimento do PEIF essa situação foi se modificando para a compreensão de que na fronteira, 
brasileiros e paraguaios formam um só povo, pois é uma única fronteira. Esta afirmação coletiva reforça a concepção de Sturza e Hatsch (2018):

\begin{abstract}
A fronteira configura-se como um espaço social; um espaço real, e também um espaço que se significa simbolicamente. Logo, a necessidade de pensarmos a fronteira não apenas como um espaço geográfico configurado pelo contato, permeabilidade, troca, mistura, hibridismo, mestiçagem cultural e étnica que se estabelecem nessa zona. Mas como uma rica e completa soma dos mais diversos fatores, dentre eles o linguístico (STURZA E HATSCH $(2018$, p. 88).
\end{abstract}

Com relação ao preconceito entre brasileiros e paraguaios, situação comum na fronteira, a adesão ao PEIF significou uma quebra de paradigma, a qual Haygert e Sturza (2015) relatam:

\begin{abstract}
Grande parte dos professores e alunos envolvidos no PEIF, em algum momento, sentiram-se ou se sentirão "divididos" entre a visão do outro como invasor do "seu território" ou somente como o outro, alguém de lingua e cultura diferente com quem tem muito a aprender e, também, muito a ensinar (HAYGERT E STURZA, 2015, p. 12).
\end{abstract}

A visão preconceituosa da fronteira, tanto de quem reside, quanto das pessoas que vem de fora, por conta da cultura e da língua diferente, representa uma situação comum na vida escolar das crianças, as quais sofrem violência psicológica e, mesmo assim, em meio as dificuldades impostas conseguem transpor as barreiras e superar os desafios (PEREIRA, 2014). Essa realidade se aplica, principalmente, as crianças paraguaias que estudam no Brasil. A partir desse cenário, Pereira (2014) ainda enfatiza que o preconceito está implícito no cotidiano das pessoas e que os paraguaios só buscam uma vida melhor para as suas crianças:

Tanto as crianças quanto seus pais desejam a escola brasileira mas, estando nela, sentem necessidade de ajustar e alinhar sua identidade na relação com os colegas e professores brasileiros. A escola brasileira é pública, e por esta razão, os pais não desembolsam para manter seus filhos estudando; os alunos recebem kit escolar, o que se coloca como mais um atrativo para que as famílias optem por manter seus filhos nesta escola (PEREIRA, 2014. p. 21).

Interfaces da Educ., Paranaíba, v.11, n.32, p. 244 - 270, 2020 
Torna-se relevante ouvir as participantes do grupo sobre como avaliam o PEIF enquanto formação continuada para professores atuantes na fronteira. A primeira a iniciar a diálogo foi AE (2018) ao dizer:

[...] eu observo e digo que eu gosto da escola e, penso internamente, porque nem tudo podemos falar abertamente, penso eu que eles (os professores de outras escolas) têm um pensamento muito atrasado porque nós estamos a frente deles e nós temos outro pensamento, outro olhar no aprender, de ensinar a criança (AE, 2018).

Já P2 (2018) complementa: "O PEIF simbolizou a concretização daquela parte que a gente só fica na teoria, então eles (alunos) aprendem mais, vão além na pesquisa, você passa uma pesquisa hoje amanhã já esta vindo com três diferentes, os alunos falam: [mas eu achei isso aqui...]" (P2, 2018).

P1 (2018) quis retomar a fala de AE (2018) e disse:

$[\ldots]$ as colegas sempre nos questionam por que trabalhamos aqui, que aqui é um excesso de trabalho e como ela disse, lá fora existe um retrocesso dentro da educação porque eles não têm o conhecimento de que nós temos, a vivência que nós temos, eu como professora gostaria muito que elas (demais professoras de outras escolas) tivessem a sorte de ter o conhecimento que nós temos (P1, 2018).

E, P1 (2018) exemplificou: “[...] nesses momentos quando tínhamos os cursos nós estudávamos, mas hoje ainda continuamos estudando" (P1, 2018). Observa-se que o PEIF representou um grande salto na aquisição de conhecimento enquanto profissional da educação para as professoras participantes do Programa e entrevistadas no grupo. Por outro lado, pelo relato das professoras e para os demais professores do município o PEIF simbolizou um trabalho árduo e dificil, mesmo não conhecendo na essência sua execução dentro da Escola. Dessa forma, Haygert e Sturza (2015) salientam que a participação no PEIF para os professores representou um repensar a prática pedagógica na fronteira:

Interfaces da Educ., Paranaíba, v.11, n.32, p. 244 - 270, 2020 
O envolvimento com o Programa permite que os fronteiriços peifianos repensem: ser fronteiriço; ser considerado fronteiriço; o respeito à diversidade; o reconhecimento à importância do outro; os preconceitos construídos devido a fatos históricos [...] (HAYGERT E STURZA, 2015, p.12).

A (2018) complementa a exemplificação de P1 (2018): “[...] tem aluno que mora do outro lado da cidade, porque eu mesmo moro para lá e eu dou aula nos dois (estado e município), moro no bairro Ipê II, tem alunos que moram em bairros como Copa, Independência e vem estudar aqui” (A, 2018). Ou seja, são bairros relativamente distantes da Escola pesquisada, para a realidade do município. Nesse momento P1 (2018) novamente exemplifica: "Lá (outras escolas) ninguém me dá bola... os alunos dizem. Porque chega lá é o professor tradicional, [eu mando, eu falo e vocês tem que aprender!]. Já aqui não você trás, você pesquisa, você vai ter conhecimento, trazer e distribuir para os colegas" (P1, 2018). Observa-se pela fala das professoras em que os alunos que experienciam o Ensino via Projetos de Aprendizagem (EPA) tem dificuldade em voltar a estudar em outra metodologia, isso presume que a capacidade inovadora proposta pelo PEIF é confirmada por Silva (2014):

A metodologia proposta pelos projetos de aprendizagem provoca esse repensar da educação e requer o acompanhamento das questões pedagógicas para provocar mudança de paradigma. Não é simples mudar um paradigma secular voltado ao o quê e como se ensino e o que entende por aprendizagem (SILVA, 2014. p. 27).

E CP (2018) trouxe uma informação até então não mencionada pelas professoras:

As vezes sentia que faltava (informação) porque queriamos mas ficávamos com pontos de interrogação, as vezes não entendíamos, porque inicialmente aderimos ao Programa sem teoria nenhuma e só depois de alguns anos, 4 ou 5 anos depois vieram as formações acompanhadas de teoria. Aí que começou a fazer sentido (CP, 2018).

Interfaces da Educ., Paranaíba, v.11, n.32, p. 244 - 270, 2020 
CP (2018) referiu ao período em que o IPOL prestava assessoria técnica para o desenvolvimento do PEBF na Escola pesquisada sem um comprometimento com formação continuada. Essa situação foi modificada por meio do Documento Marco Referencial de Desenvolvimento Curricular, criado e aprovado no âmbito do Mercosul com a instituição do PEIF, em que as universidades seriam parceiras para o desenvolvimento de formação continuada para os professores de fronteira.

Mediante os apontamentos apresentados pelos sujeitos no grupo focal é evidente notar que o PEIF foi um programa inovador ao considerar as particularidades presentes nas regiões de fronteiras. Além disso, ao articular o processo formativo junto às universidades públicas brasileiras, possibilitou um espaço sistematizado para a orientação do processo de formação continuada dos professores que atuam nas escolas fronteiriças. Por outro lado, o Programa enquanto uma política supranacional esbarrou em inúmeros limites, dentro os quais, destaca-se a ausência de outras instituições de ensino de educação básica participando do Programa e a sua consequente descontinuidade como uma política de integração regional dos países membros do Mercosul.

É importante registrar que o PEIF teve a durabilidade entre 2012 e 2015. O pouco tempo de vigência do programa é um importante sinalizador dos obstáculos presentes na pactuação de politicas educacionais entre os países da América do Sul, em especial, do Mercosul. Esse quadro demonstra um grave entrave para a consolidação da integração regional do bloco, uma vez que, segundo Catani (2000, p. 56), a educação tem ocupado papel relevante nas estratégias de desenvolvimento dos países, "[...] tornando-os mais competitivos frente aos desafios do processo de globalização/regionalização, bem como, fortalecimento dos laços culturais e sociais entre os países envolvidos para a construção de uma transnação". 


\section{Considerações Finais}

O PEIF apresentou uma proposta inovadora ao estabelecer parceria entre MEC, as universidades e as escolas na fronteira, como caso do sul do MS, entro o Brasil e o Paraguai, na busca pela integração entre os dois países. Contudo, não ocorreu o cruce entre todas escolas brasileiras e paraguaias dessa região, bem como poucas escolas realizaram a adesão ao Programa.

Acrescenta-se como fator limitante à adesão pelas demais escolas de fronteira ao PEIF a necessidade de alterar a proposta pedagógica objetivando contemplar a adoção do EPA e dos mapas conceituais como metodologia de ensino. A alteração da proposta pedagógica tinha o intuito de repensar a prática no âmbito da instituição, como evidenciaram as professoras no grupo focal, ou seja, sair da zona de conforto e tornarem-se estudiosos do conteúdo abordado na perspectiva da aprendizagem significativa. Pereira (2016, p. 204) enfatiza que "[...] com a proposta implementada pelo PEIF, a escola deixou de ser coadjuvante para ser protagonista na construção de uma política educacional diferenciada para aquela região de fronteira". Esse cenário foi determinante para que no Sul do estado de Mato Grosso do Sul tivesse apenas uma escola que aderiu, efetivamente, ao Programa, o que também representou prejuízos a proposta da política.

Outro aspecto evidenciado no grupo focal relaciona-se as diferenças entre o PEBF e o PEIF. Como já mencionado, o PEBF tinha o IPOL como fonte de assessoramento pedagógico para as escolas participantes, a realização do cruce e a formação continuada mensal. O PEIF, por sua vez, estabeleceu a parceria entre MEC, universidades, secretarias estaduais e municipais de educação por meio das escolas gêmeas, fomentando desse modo, a realização de formação continuada semanal. Logo, a grande diferença entre os dois programas estava na realização de formação para os professores com periodicidade, o que para sujeitos da pesquisa foi 
fundamental a regularidade do processo formativo, pois trouxe a aproximação com a teoria envolvida na educação de fronteira.

As diferenças apresentadas entre os Programas têm na formação continuada de professores o seu ponto chave, de acordo com o grupo focal, participar do PEIF representou compreender a diversidade em que a Escola pesquisada estava envolta e, também, repensar o caminho metodológico adotado, associando assim a teoria e a prática em sala de aula.

Para os sujeitos da pesquisa, a chegada do PEIF e a consequente formação continuada representou uma oportunidade de compreender, teoricamente, a relevância da diversidade cultural presente na fronteira, além de construir uma identidade cultural respeitando ao multilinguismo, valorizando o ensino em linguas e não de línguas.

Se por um lado observa que o PEIF foi um programa singular ao considerar na sua proposta um olhar específico para as características de escolas que estão situadas em região fronteiriças a partir de um processo formativo sistematizado e periódico, por outro, a intenção em se consolidar enquanto uma politica supranacional de integração regional não se materializou.

Lorenzetti e Torquato (2016, p. 99) esclarecem que o PEIF não atingiu seu propósito como uma política supranacional, pois para os autores, ainda que nos discursos oficiais o PEIF foi pensado como um propulsor de integração regional e intercultural, na prática ficou refém de iniciativas isoladas e sem continuidade. "Uma verdadeira questão macropolítica, como é um processo de integração regional e internacional, não pode ser uma tarefa para ser desenvolvida, desde o nível micropolítico pela escola”.

Frente ao exposto, evidencia-se a proposta do PEIF como uma importante estratégia para tratar a problemática das especificidades da formação docente para professores que atuam em instituições de ensino na região de fronteira, mas pela morosidade das ações e pela descontinuidade 
do Programa, não se efetivou como uma política supranacional no âmbito do Mercosul.

\section{Referências}

ALARCÃO, I. Escola Reflexiva e Nova Racionalidade. 4 ed. Artes Médicas. 2001.

BABINSKI, Daniel B. de O. O direito à educação básica no âmbito do Mercosul: proteção normativa nos planos constitucional, internacional e regional. 2010. 182f. Dissertação (Mestrado em Direito) - Faculdade de Direito, Universidade de São Paulo, São Paulo, 2010.

BALLER, L. Fronteira e fronteiriços: A construção das relações sociais e culturais entre brasileiros e paraguaios (1954-2014). Dourados: UFGD, 2014. Tese de doutorado, Universidade Federal da Grande Dourados.

BARDIN, L. Análise de conteúdo. Ed. rev. e amp. 3 reimp. São Paulo: Edições 70. 2016 .

BERNARDO, L. V. M. "Além das Palauras": experiências de um projeto de intervenção em uma Escola de Dourados/MS. VII Encontro de Produção Científica e Tecnológica (EPCT): Ética da pesquisa científica. De 22 a 26 de outubro de 2012. Faculdade Estadual de Ciências e Letras de Campo Mourão. Núcleo de Pesquisa Multidisciplinar. Campo Mourão: FECILCAM/NUPEM, 2012.

BRASIL. Ministério da Educação, Ministerio de Educación, Ciencia y Tecnologia. Escolas de Fronteira. Brasilia e Buenos Aires. 2008.

BRASIL. Portaria n. 798, de 19 de junho. Institui o Programa Escolas Interculturais de Fronteira, que visa a promover a integração regional por meio da educação intercultural e bilíngue. 2012. 
BRASIL. Resolução n. 2, de 01 de julho. Define as Diretrizes Curriculares Nacionais para a formação inicial em nível superior (cursos de licenciatura, cursos de formação pedagógica para graduados e cursos de segunda licenciatura) e para a formação continuada. 2015.

BRASIL. Decreto n. 8.752, de 9 de maio de 2016. Dispõe sobre a Política Nacional de Formação dos Profissionais da Educação Básica. 2016.

CARLOMAGNO, M. C. ROCHA, L. C. da. Como criar e classificar categorias para fazer análise de conteúdo: uma questão metodológica. In: Revista Eletrônica de Ciência Politica, Curitiba, vol. 7, n. 1. p. 173-188, 2016.

CATANI, A. F. América Latina: impasses e alternativas. São Paulo: Humanistas, 2000.

CELLARD, A. A análise documental. In: POUPART, J. DESLAURIERS, J.P. GROULX, L. (Orgs.). A pesquisa qualitativa: enfoques epistemológicos e metodológicos. Petrópolis: Vozes, p. 295 - 334. 2008.

GATTI, B. A. Grupo focal na pesquisa em Ciências Sociais e Humanas. Brasília: Líber Livro. 2005.

GONDIM, S. M. G. Grupos focais como técnica de investigação qualitativa: desafios metodológicos. In: Paidéia, São Paulo, v. 12, n. 24, p. 149-161, 2003.

HAYGERT, S. STURZA, E. R. Reflexões sobre o Programa de Escolas Interculturais de Fronteira como uma política linguística. In: Linguagens $e$ Cidadania, Santa Maria, v. 17, jan./dez. p. 1-14, 2015.

LIMA, E. F. F. O sistema educacional diferenciado como um direito humano e fundamental para as regiões de fronteira. Dissertação de Mestrado. Dourados: Universidade Federal da Grande Dourados. 2018. 
LORENZETTI, A. TORQUATO C. P. O Programa Escolas Interculturais de Fronteira (PEIF) como política linguística. In: Matraga, Rio de Janeiro, v.23, n.38, jan/jun. 2016.

MAINARDES, J. Abordagem do ciclo de políticas: uma contribuição para a análise de políticas educacionais. In: Educação e Sociedade, Campinas, v. 27, n.94, p.47-69. 2006.

MOREIRA, M. A. Aprendizagem significativa em mapas conceituais. Porto Alegre: UFRGS, Instituto de Física. 2013.

PALUMBO, D. J. A abordagem de política pública para o desenvolvimento político na América. In: Politica de capacitação dos profissionais da educação. Belo Horizonte: FAE/IRHJP. p. 35-61. (Original: PALUMBO, Dennis J. Public Policy in América - Government in Action. 2. ed. Tradução: Adriana Farah. Harcourt Brace \& Company, 1994. Cap. 1, p. 8-29). 1989.

PEREIRA, M. C. Um breve estado de arte do Programa das Escolas Interculturais de Fronteira (PEIF) - 10 anos em favor da cultura para a paz. In: PINTO, A. C. T. SILVA, M. R. da. Programa Escola Interculturais de Fronteira (PEIF): 10 anos. Tubarão: Copiart. 2016.

PEREIRA, M. C. Experiências, vivências e o imaginário na fronteira seca do sul de Mato Grosso do Sul. In: BRASIL, TV Escola. Salto para o Futuro: Escolas Interculturais de Fronteira. Ano XXIV - Boletim 1. Maio. 2014. PRETTI, D.; URBANO, H. A linguagem falada culta na cidade de São Paulo. São Paulo: Queiroz, 1988.

RICHARDSON, R. et. al. Pesquisa social: métodos e técnicas. 3 ed. São Paulo: Atlas. 2008. 
RONCA, A. C. C. Teoria de Ensino: a contribuição de David Ausubel. In: Temas em Psicologia. n. 03. PUC. São Paulo. 1994.

SALDAÑA, J. The Coding Manual for Qualitative Researches. Sage. 2013.

SILVA, P. A. O Programa Escolas Interculturais de Fronteira como propulsor de políticas públicas educacionais. In: PINTO, A. C. T.; SILVA, M. R. da. De frente para a fronteira: reflexões sobre educação em área de fronteira. Chapecó. 2014.

SCHRAIBER, L. B. Pesquisa qualitativa em saúde: reflexões metodológicas do relato oral e produção de narrativas em estudo sobre a profissão médica. In: Revista de Saúde Pública, São Paulo, v. 29, n. 1, p. 63-74. 1995.

SOUZA, K. R. Direito à educação nos países membros do Mercosul: um estudo comparado. 2017. 346f. Tese (Doutorado em Educação Escolar), Universidade Estadual Paulista, Araraquara-SP, 2017.

STURZA, E. R. Das experiências e dos aprendizados no Programa Escolas Interculturais de Fronteiras. In: BRASIL, TV Escola. Salto para o Futuro: Escolas Interculturais de Fronteira. Ano XXIV - Boletim 1. Maio. 2014.

STURZA, E. R. TATSCH, J. A fronteira e as línguas em contato: uma perspectiva de abordagem. Cadernos de Letras da UFF Dossiê: Línguas e culturas em contato. n. 53. 2018.

TORCHI, G. da F. C. SILVA, C. P. da. O retrato da fronteira Sul-MatoGrossense por meio da expansão do Programa Escola Interculturais de Fronteira. In: PINTO, A. C. T.; SILVA, M. R. da. Programa Escola Interculturais de Fronteira (PEIF): 10 anos. Tubarão: Copiart. 2016. 